\title{
Conversaciones de paz en Afganistán
}

\section{Silvana Barrios ${ }^{1}$}

\section{Contribución en la Sección Debates Internacionales}

Resumen: Tras una serie de conflictos armados de extensa duración (desde la invasión soviética de 1979), que no solamente dejó a Afganistan devastado, sino que produjo una dislocación de la sociedad afgana (Hakami, 2011), el país se encuentra hoy en una circunstancia en la que todos los actores reconocen que no se puede lograr una solución militar después de tantos años de guerra, con un deseo generalizado de los afganos de obtener una paz sostenible. La situación de seguridad ha empeorado en los últimos años, alcanzando las tasas de bajas civiles un terrible récord en 2018. Desde que se alcanzó el acuerdo entre Estados Unidos y los talibanes en febrero de 2020, se han observado pocos progresos en el proceso de paz afgano más amplio y la violencia se ha desatado (UNAMA; 2019). De acuerdo a las Naciones Unidas, 1.300 civiles murieron y se registró un aumento del 33 \% en las muertes causadas por los talibanes en los primeros seis meses de este año (Mashal y Rahim, 2020; UNAMA, 2020).El acuerdo entre Estados Unidos y los talibanes señala 4 objetivos: 1) Los grupos armados (talibanes y fuerzas de seguridad afgana) no podrán utilizar Afganistán como base para actos contra Estados Unidos y sus aliados, 2) Las fuerzas extranjeras se retirarán de Afganistán, incluidas las tropas y contratistas estadounidenses y las fuerzas de la coalición, 3) Las negociaciones intraafganas comenzarán el 10 de marzo de 2020 (se sabe ya que esa fecha se demoró) y 4) La agenda para esas negociaciones incluirá un debate sobre cómo implementar un alto el fuego permanente y completo, al tiempo que una hoja de ruta política para el futuro de Afganistán.

Tras una serie de conflictos armados de extensa duración (desde la invasión soviética de 1979), que no solamente dejó al país devastado, sino que produjo una dislocación de la sociedad afgana (Hakami, 2011), el país se encuentra hoy en una

1 Docente-investigadora; miembro del Grupo de Trabajo sobre Asia del Sur, del Comité de Asuntos Asiáticos, del Consejo Argentino para las Relaciones Internacionales/CARI (CABA, República Argentina). Correo electrónico: silvan_barrios@yahoo.com.ar 
circunstancia en la que todos los actores reconocen que no se puede lograr una solución militar después de tantos años de guerra, con un deseo generalizado de los afganos de obtener una paz sostenible.

La situación de seguridad ha empeorado en los últimos años, alcanzando las tasas de bajas civiles un terrible récord en 2018. Desde que se alcanzó el acuerdo entre Estados Unidos y los talibanes en febrero de 2020, se han observado pocos progresos en el proceso de paz afgano más amplio y la violencia se ha desatado (UNAMA, 2019). De acuerdo a las Naciones Unidas, 1.300 civiles murieron y se registró un aumento del $33 \%$ en las muertes causadas por los talibanes en los primeros seis meses de este año (Mashal y Rahim, 2020; UNAMA, 2020).

El acuerdo entre Estados Unidos y los talibanes señala cuatro objetivos: (1) Los grupos armados (talibanes y fuerzas de seguridad afgana) no podrán utilizar Afganistán como base para actos contra Estados Unidos y sus aliados, (2) Las fuerzas extranjeras se retirarán de Afganistán, incluidas las tropas y contratistas estadounidenses y las fuerzas de la coalición, (3) Las negociaciones intra-afganas comenzarán el 10 de marzo de 2020 (se sabe ya que esa fecha se demoró) y (4) La agenda para esas negociaciones incluirá un debate sobre cómo implementar un alto el fuego permanente y completo, al tiempo que una hoja de ruta política para el futuro de Afganistán. De acuerdo a diversos reportes, el acuerdo incluye anexos clasificados (Center for Preventive Action, 2020).

El inicio de las negociaciones se retrasó debido a desacuerdos sobre la liberación de prisioneros, una de las condiciones previas de los talibanes para participar de las mismas. El gobierno afgano y los talibanes se habían comprometido a liberar a 5.000 y 1.000 prisioneros respectivamente, pero los últimos 400 prisioneros talibanes habían sido acusados o condenados por delitos graves (BBC News, 2020). De hecho, el presidente afgano, Ashraf Ghani, sólo tomó la decisión de liberar a esos prisioneros después de convocar a una asamblea consultiva o Loya Jirga. Los prisioneros fueron liberados el 26 de marzo, aunque el gobierno solicitó garantías de que no volverían a la lucha (Aljazeera, 2020a).

El mismo día de la firma de ese acuerdo, el secretario de Defensa de Estados Unidos, Mark T. Esper, el secretario de la OTAN, Jens Stoltenberg, y el presidente afgano Ashraf Ghani, firmaron una declaración conjunta, en la que también se identifican cuatro objetivos: (1) Evitar que los grupos terroristas utilicen Afganistán 
como base para ataques contra Estados Unidos y sus aliados, (2) Establecer un cronograma de retiro de todas las tropas extranjeras de Afganistán, (3) Acordar un arreglo político para el futuro de Afganistán, tras las negociaciones intra -afganas y (4) Establecer un alto el fuego permanente y completo (Center for Preventive Action, 2020).

El gobierno y los talibanes acordaron que la ronda de apertura se llevaría a cabo en Doha, Qatar y que no habría participación de ningún extranjero y en línea con ello, las conversaciones, se iniciaron el 12 de septiembre, siendo las primeras conversaciones oficiales directas entre ambos. El cronograma fijado en el acuerdo entre Estados Unidos y los Talibanes para la eventual retirada de las tropas extranjeras señala mayo de 2021 como fecha final, pero sostiene que la retirada se basaría en condiciones, como la de que el acuerdo fuera aceptable para los afganos y los Estados Unidos. Los intereses estadounidenses se alinean con los del gobierno afgano y el futuro apoyo financiero internacional dependerá del acuerdo, resultando esto fundamental para todos. Aún cuando culminar las conversaciones no sea sencillo, la prioridad inmediata del gobierno afgano será un alto al fuego, al tiempo que la principal variable de influencia de los talibanes es precisamente la violencia (Kermani, 2020).

El negociador principal del gobierno afgano es Massoum Stanekzai, que dirigió los esfuerzos de paz durante muchos años, bajo el ex presidente Karzai y dirige a otros 20 delegados que reflejan la diversidad del país (habiendo incluido sólo cinco mujeres). Por su parte, el negociador principal de los talibanes es Abdul Ghani Baradar, número dos de los talibanes, mientras que el principal negociador en la sala es Sher Mohammad Abbas Stanekzai. Cabe destacar el hecho de que, a poco de iniciar las conversaciones de paz, Fawzia Koofi, mujer del grupo negociador del gobierno afgano sufrió un atentado, aunque resultó sólo con heridas menores (RFE/RL, 2020).

Singh, Smith, Worden, Ahmadi and Walsh (2020) apuntan cinco cuestiones a destacar en el marco de estas conversaciones de paz: (1) Las negociaciones exitosas entre los afganos ofrecen a Estados Unidos la forma más responsable de poner fin a la guerra más larga de Estados Unidos (la disposición de Estados Unidos para reunir asistencia económica internacional para Afganistán proporciona una ventaja clave, dada la conciencia de todos de tal necesidad), (2) como se señaló, esta es la primera vez que las partes beligerantes en el conflicto afgano negociarán directamente, (3) El gobierno afgano y los talibanes deberán reconciliar sus diferencias centrales acerca del sistema de gobierno del país (mientras el Ministro de Relaciones Exteriores afgano, 
Mohammed Haneef Atmar señaló que la voluntad de los afganos es mantener "una democracia constitucional" y "un sistema político inclusivo", no queda todavía claro cuán abiertos están los talibanes respecto a concesiones en su demanda de emirato islámico para el actual Afganistán, ni quién/nes decide/n qué leyes están de acuerdo con el Islam en el país?), (4) Para que un acuerdo sea duradero, debe proteger y promover los derechos de las mujeres afganas y (5) Los talibanes consideran con seriedad las conversaciones, pero actualmente no creen que deban dar mucho.

Mientras tanto, continúa siendo relevante el rol de otros actores, como el caso de Pakistán, en tanto una paz sostenible requerirá que ni Afganistán, ni la región entre Afganistán y Pakistán, se conviertan en zonas de refugio seguro del terrorismo internacional. El ministro de Relaciones Exteriores de Pakistán, Shah Mahmood Qureshi sostuvo una reunión con una delegación de talibanes, encabezada por Baradar, contando también con la presencia del General Faiz Hameed (quien dirige la Agencia de Inteligencia pakistaní/ISI), tras la cual declaró que Pakistán espera con ansia el inicio del diálogo intra-afgano, para asegurar la paz y estabilidad regionales (Aljazeera, 2020b).

Por otro lado, mientras doce países se han ofrecido a albergar estas negociaciones de paz (Uzbekistán, Turkmenistán, Kazakhstán, China, Rusia, Turquía, Irán, Qatar, Indonesia, Japón, Noruega y Alemania) (Afghan Voce Agency, 2020), señalando ello un fuerte apoyo a las mismas, el Ministro de Relaciones Exteriores afgano, Atmar, señaló que en torno de las conversaciones de paz, el gobierno de Afganistán está "trabajando muy de cerca con China" (cabe recordar que estas conversaciones constituyen una inversión estratégica para combatir el terrorismo internacional en la región) (Dhaka, 2014). Agregó además que también trabaja con las naciones de Asia central, buscando construir Afganistán como un "centro" regional para el comercio y la inversión, que contribuya a conectar esas naciones con mercados más distantes (USIP Staff, 2020). Como es conocido, los países de Asia central, han estado muy involucrados en los acontecimientos en Afganistán desde la invasión soviética de 1979 y durante las últimas dos décadas, esa región proporcionó acceso a Afganistán a las tropas y suministros de la OTAN, mientras en la actualidad, brindan apoyo de asistencia extranjera, acceso al mercado ruso, europeo, etc. (Gallagher, 2020). Cabe recordar además que Afganistán conecta diversas partes del continente asiático, de modo que ya pacificado podría obrar de puente entre el centro y el sur de Asia, regiones 
que requieren mayor integración (Laruelle, Peyrouse y Axyonova, 2013). Incluso la iniciativa C5 + 1 del Departamento de Estado norteamericano, que consta de los 5 países de Asia Central y Estados Unidos y que fue establecida en 2015, podría incluir de manera más significativa a Afganistán, profundizando la integración regional (Walker y Keraney, 2016).

Finalmente, la expectativa de mejora en la calidad de vida de las personas y la prosperidad de los países en la región, queda estrechamente ligada a las perspectivas de paz en Afganistán.

\section{Referencias}

Afghan Voce Agency (16 de julio de 2020). Twelve countries offer to host intraAfghan peace talks. Afghan Voce Agency.

https://www.avapress.com/en/news/214694/twelve-countries-offer-to-hostintra-afghan-peace-talks

Aljazeera (9 de agosto de 2020a). Afghan president agrees Taliban prisoner release. Aljazeera. https://www.aljazeera.com/news/2020/8/9/afghan-presidentagrees-taliban-prisoner-release

Aljazeera (25 de agosto de 2020b). Pakistan urges Taliban to start peace talks with Afghan gov't. Aljazeera.

https://www.aljazeera.com/news/2020/8/25/pakistan-urges-taliban-to-startpeace-talks-with-afghan-govt

BBC News (12 de septiembre de 2020). Afghan-Taliban peace talks an "opportunity for peace". BBC News. https://www.bbc.com/news/world-asia-53976968

Center for Preventive Action (11 de septiembre de 2020). What to Know About the Afghan Peace Negotiations. Council on Foreign Relations. https://www.cfr.org/article/what-know-about-afghan-peace-negotiations

Dhaka, A. (2014). Factoring Central Asia into China's Afghanistan policy. Journal of Eurasian Studies, 5(1), 97-106. https://www.sciencedirect.com/science/article/pii/S1879366513000286

Gallagher, A. (28 de julio de 2020). Afghanistan: Can Central Asia Help Spur Peace with the Taliban? USIP. 
https://www.usip.org/publications/2020/07/afghanistan-can-central-asiahelp-spur-peace-taliban

Hakami, A. (2011). La tragedia afgana en el marco de la geopolítica mundial. Boletín de Información, (319), 51-60. https://dialnet.unirioja.es/ejemplar/291873

Kermani, S. (7 de septiembre de 2020). Taliban peace talks: What to expect from the new round? BBC News. https://www.bbc.com/news/world-asia-54016760

Laruelle, M., Peyrouse, S. y Axyonova, V. (2013). The Afghanistan-Central Asia relationship: What role for the EU? EUCAM Working Paper No. 13. Finland: FRIDE and the Karelian Institute of the University of Eastern Finland. https://www.files.ethz.ch/isn/159880/EUCAM_WP13_Afghanistan.pdf

Mashal, M. y Rahim, N. (27 de julio de 2020). Taliban Executes Female Prison Guard, and U.N. Raises Concern Over Afghan Violence. The New York Times. https://www.nytimes.com/2020/07/27/world/asia/taliban-executesguard-afghanistan.html

RFE/RL (15 de agosto de 2020). Afghan Peace Negotiator Survives Assassination Attempt. RadioFreeEurope/RadioLiberty. https://www.rferl.org/a/afghanpeace-negotiator-survives-assassination-attempt/30785053.html

Singh, V. J., Smith, S., Worden, S., Ahmadi, B. y Walsh, J. (14 de septiembre de 2020). Five Things to Know About the Afghan Peace Talks. USIP. https://www.usip.org/publications/2020/09/five-things-know-about-afghanpeace-talks

UNAMA (United Nations Assistance Mission in Afghanistan) (24 de febrero de 2019). Civilians deaths from Afghan conflict in 2018 at highest recorded level-UN report. UNAMA. https://unama.unmissions.org/civilian-casualtiesafghanistan-spike-record-high-levels-\%E2\%80\%93-un-report

UNAMA (United Nations Assistance Mission in Afghanistan) (2020). Afghanistan.

Protection of Civilians in Armed Conflict. Midyear report: 1 January-30 June 2020.

https://unama.unmissions.org/sites/default/files/unama_poc_midyear_report _2020_-_27_july.pdf

USIP Staff (28 de agosto de 2020). Afghan Government: 'Optimistic' on Opening Talks with Taliban. USIP. 
https://www.usip.org/publications/2020/08/afghan-government-optimisticopening-talks-taliban

Walker, J. y Kearney, K. (16 de septiembre de 2016). What Central Asia Means to the United States.The Diplomat. https://thediplomat.com/2016/09/what-centralasia-means-to-the-united-states/ 